\title{
Do Asia-Pacific Region Universities Need a Recognition Framework for Foreign Educational Credentials? Implications of Survey Data from Japan
}

\author{
Takashi Sekiyama \\ Toyo University, Tokyo, Japan \\ Email: sekiyama@toyo.jp
}

How to cite this paper: Sekiyama, T. (2018). Do Asia-Pacific Region Universities Need a Recognition Framework for Foreign Educational Credentials? Implications of Survey Data from Japan. Creative Education, 9, 368-379.

https://doi.org/10.4236/ce.2018.93026

Received: February 1, 2018

Accepted: March 9, 2018

Published: March 12, 2018

Copyright $\odot 2018$ by author and Scientific Research Publishing Inc. This work is licensed under the Creative Commons Attribution International License (CC BY 4.0).

http://creativecommons.org/licenses/by/4.0/

(c) (i) Open Access

\begin{abstract}
This paper explores whether Asia-Pacific universities deem it necessary to systematically evaluate and recognize academic qualifications and credentials obtained in foreign countries. The international framework for facilitating the recognition of foreign qualifications was established by UNESCO. The Asia-Pacific Regional Convention on the Recognition of Qualifications in Higher Education 2011 was entered into force in February 2018. However, only a few of UNESCO's Asia-Pacific member states have ratified it. Considering the rapid internationalization of higher education in Europe, the slowness of some Asia-Pacific states to establish a recognition framework for foreign credentials is a mystery. This paper explores the idea that Asia-Pacific countries' universities do not feel a need to systematically evaluate foreign credentials because their international student bodies are small. The results of questionnaire surveys in Japan imply that the progress in internationalization seems to be key to extending foreign credential evaluation to the UNESCO Asia-Pacific member states. A focus on promoting student mobility in the region might encourage ratifications of the Asia-Pacific Regional Convention on the Recognition of Qualifications in Higher Education (Tokyo Convention).
\end{abstract}

\section{Keywords}

International Education, Foreign Credentials, National Information Center, 2011 Tokyo Convention, Recognition of Qualifications, Access to Higher Education

\section{Introduction}

The global revolution in transportation and communication technology has 
significantly increased the movements of people around the world. Some people travel for leisure and recreational purposes, whereas others seek permanent work in foreign countries. Some people want freedom and prosperity and others are fleeing threats to their personal safety or environmental disasters. Some people move to foreign countries for educational opportunities. Countries are influenced by this increased immigration in their economies, politics, and academic institutions.

In many countries, universities and colleges have unavoidably become part of a global educational network sustained by the international mobility of students and professionals, which is increasingly easy, and competition is intense among universities to secure the best and brightest students and professionals. However, when students or professionals enter a new country, they tend to have difficulties transferring their academic and professional credentials because national standards for awarding these credentials and the nature of the qualifications are diverse, often requiring reassessment. Because many skilled labor markets are becoming internationalized and international student bodies are growing, the demand is growing for a standardized framework for recognition of academic and professional credentials and qualifications (OECD, 2004).

UNESCO established an international framework to facilitate the recognition of foreign academic credentials and qualifications through a series of regional conventions, starting in Latin America and the Caribbean in 1974, which aimed to create mutual recognitions of academic credentials among member countries. Further, UNESCO has started an updating process to account for changes in higher education, such as massification and internationalization. The 1997 Convention on the Recognition of Qualifications concerning Higher Education in the European Region (Lisbon Recognition Convention) and the Recognition of Studies, Certificates, Diplomas, Degrees and Other Academic Qualifications in Higher Education in African States (2014 Addis Convention) are second-generation regional conventions in the process of being ratified.

However, only a few of UNESCO's Asia-Pacific members have ratified the 2011 Asia-Pacific Regional Convention on the Recognition of Qualifications in Higher Education (Tokyo Convention). Japan and South Korea deposited their instruments of accession to the Tokyo Convention with UNESCO in December of 2017 (UNESCO, 2017, 2018). Australia, China, and New Zealand also are formal parties to the Tokyo Convention. However, more than six years passed before the Tokyo Convention was in force because at least five members' deposits of the instruments of accession were required. Numerous Asia-Pacific countries have yet to ratify the Tokyo Convention.

Why is ratification of the 2011 Tokyo Convention slow despite its several merits? Compared to the developments and progress being made through the Lisbon Recognition Convention and the 2014 Addis Convention, the Tokyo Convention is losing momentum toward full access, equity, and quality of higher education in the Asia-Pacific region. Perhaps lack of understanding of its benefits 
and procedural and political considerations are impeding ratifications (Chao, 2017), but that argument fails to consider that some Asia-Pacific UNESCO members simply might not have an immediate need for a systematic recognition framework for foreign credentials. Thus, it would be useful to investigate the reasons for slow ratification of the Tokyo Convention from the perspective of need.

This study explored the idea that some Asia-Pacific states do not perceive a need for evaluation and recognition of foreign academic credentials, and, if so, slow ratification would be a reasonable response. This study examined the following question: Do needs for foreign credential evaluation (FCE) and national information centers (NICs), which are key components of the Tokyo Convention, currently exist in the Asia-Pacific region? This study investigated this question using questionnaire survey data collected by the Japanese National Institute for Academic Degrees and Quality Enhancement of Higher Education (NIAD-QE). The NIAD-QE focused on FCE and NICs to identify factors related to the promotion of the Tokyo Convention, but the survey results have been published only on a few local websites and presented in seminars (Ifuku \& Hata, 2015; Mori \& Yoshikawa, 2017). Thus, this is the first study to analyze these data on the development of FCE in Japan and the Asia-Pacific region. The next section summarizes the Tokyo Convention. The following sections discuss the two NIAD-QE surveys. Then, the implications of the survey results are addressed. Based on the review of these survey data, the paper concludes that student mobility in the Asia-Pacific region might not be sufficiently active to encourage prompt ratification of the Tokyo Convention by many of the Asia-Pacific countries.

\section{The Tokyo Convention}

The Tokyo Convention in 2011 was a second-generation regional convention. The first convention was the Regional Convention on the Recognition of Studies, Diplomas and Degrees in Higher Education in Asia and the Pacific 1983 adopted in Bangkok (1983 Bangkok Convention). Twenty-one of the 48 UNESCO Asia-Pacific member states ratified it. To reflect new developments in higher education in the region, the process of updating the 1983 Bangkok Convention started in 2005. Recognizing the need for a revision, the Asia-Pacific UNESCO members agreed to amend it at the International Conference of States in Tokyo in 2011. The Tokyo Convention aimed to ensure that courses and degrees in higher education are recognized as widely as possible by considering the diversity of the region's educational systems and the variations in the cultural, social, political, religious, and economic backgrounds of the region's countries (UNESCO, 2012). The Tokyo Convention aimed to create benefits for the members by creating transparent, coherent, and reliable procedures for recognizing foreign credentials to increase international student mobility. It also aimed to increase students' educational options, which might benefit those states 
with low domestic capacity to meet demands for higher education. Accepting foreign educational credentials attracts skilled, competent, flexible workers who support national sustainable economic development (Chao, 2017).

In line with the modernization of the UNESCO Regional Conventions on the Recognition of Higher Education Qualifications, the Tokyo Convention reflects new trends on the recognition of higher educational credentials in the Asia-Pacific region. Inclusion of partial studies, non-traditional qualifications, degree supplements, development and maintenance of NICs, and qualifications held by refugees or displaced persons and those in a refugee-like situation was particularly important. The Tokyo Convention prescribes the following articles.

Articles IV.1, V.1, and VI.1: Each Party shall recognize the qualifications and prior learning obtained in the other Parties unless a substantial difference can be shown between them.

The FCE and NICs are key features of the regional framework for recognizing foreign educational qualifications and credentials. Because systems for awarding degrees significantly vary among countries, FCE is difficult without specific information provided by the member states. Thus, the Tokyo Convention states the following.

Articles VI.1 and VI.2: Each Party shall provide relevant, accurate and up-to-date information in order to facilitate the recognition of qualifications in higher education.

Article VI.3: Each Party shall take adequate measures for the development and maintenance of a national information centre.

Article X.2 states, "This Convention shall enter into force on the first day of the month following the expiration of the period of one month after five UNESCO Member States of the Asia-Pacific region have expressed their consent to be bound by the Convention." The Tokyo Convention entered into force after Japan and South Korea deposited their instruments of accession with UNESCO in December 2017. Altogether, only five member states are parties to the Tokyo Convention as of January 2018. Figure 1 illustrates the Tokyo Convention's structure.

\section{Japan's Need for FCE and NICs}

The NIAD-QE conducted a survey in Japan on the need for NICs (NIAD-QE, 2016). The survey was administered online from February 26 through April 15,

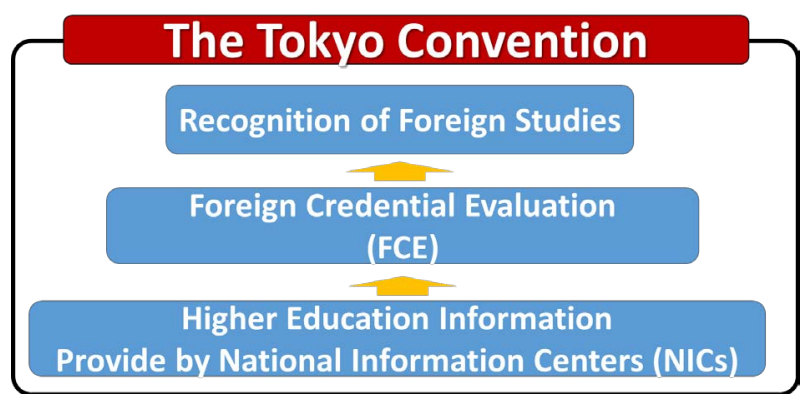

Figure 1. Foreign credential evaluation of the Tokyo Convention. 
of 2014. The target population was academic and administrative staff managing international admissions at Japan's 782 universities. The types of respondents in the sample are shown in Table 1.

The survey found that many Japanese universities had not implemented strict evaluations of foreign credentials, and more than $90 \%$ of the respondents had never suspected the authenticity of documents submitted by international applicants; just $9 \%$ of respondents at the undergraduate level and $7 \%$ of respondents at the graduate level had questioned the authenticity of submitted documentation (Figure 2). Moreover, most of the respondents did not have a prescribed process for assessing authenticity. Less than one-fourth of the institutions reported a process to evaluate documents submitted by international applicants (Figure 3).

The survey further found that Japanese universities with large international student bodies tended to implement FCE and to believe there is a need for FCE information. The larger the proportional international student body, the more the respondent believed that FCE is necessary. Figure 4 shows the variation in the opinion that FCE information is needed among universities with various proportions of international students. Respondents at universities whose international student populations were .10 or more of their student bodies were most likely to be concerned about the validity of credentials.

Similarly, the respondents at universities that were more likely to employ

Table 1. NIAD-QE respondents to survey on the need for NICs.

\begin{tabular}{cc}
\hline Type of respondents & $\mathrm{n}$ \\
\hline Evaluation of foreign undergraduate diplomas & 484 \\
Evaluation of foreign graduate diplomas & 468 \\
Recognition of foreign undergraduate credits & 469 \\
Recognition of foreign graduate credits & 425
\end{tabular}

Source: NIAD-QE, 2016.

Question:

"Ever suspected the authenticity of the submitted documents?"

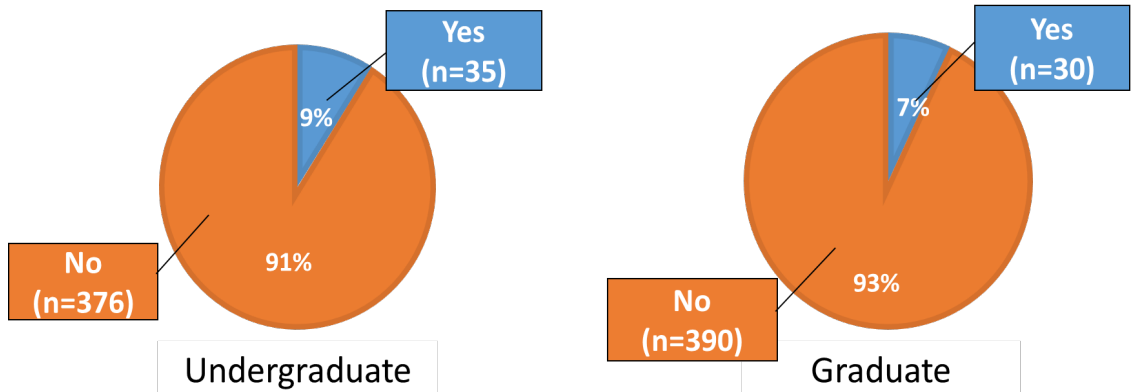

Figure 2. Attitude toward authenticity of submitted documents (source: NIAD-QE, 2016). 
Question:

"A prescribed process to assess the authenticity of the documents?"
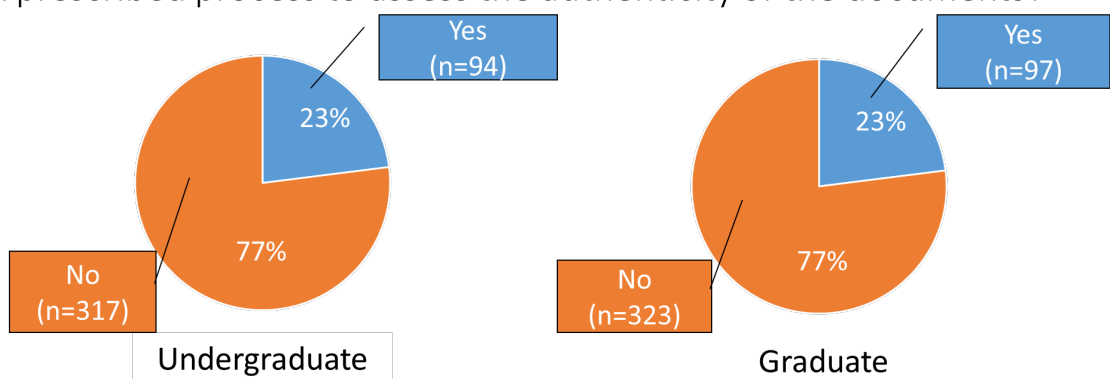

Figure 3. Prescribed process to assess authenticity of submitted documents (source: NIAD-QE, 2016).

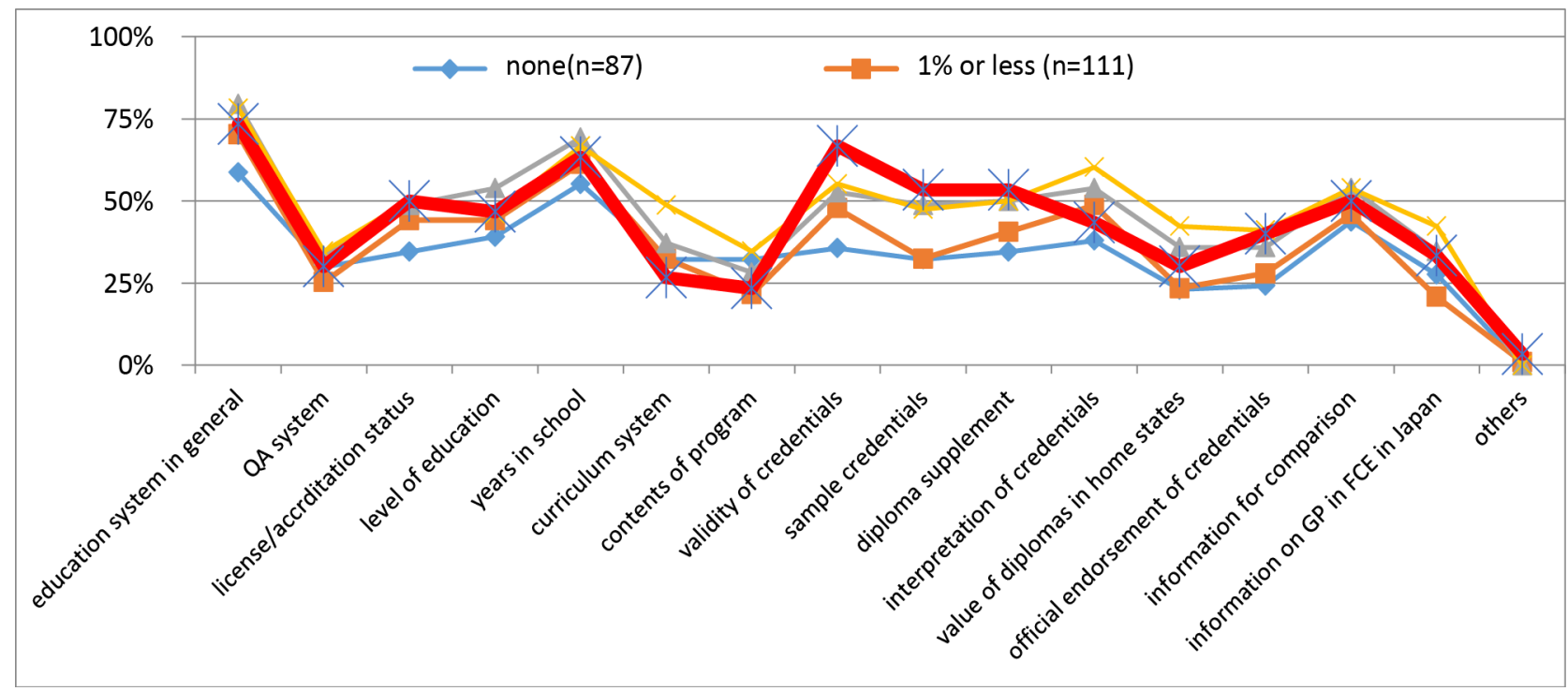

Figure 4. Various aspects of need for foreign credential evaluation by proportion of international students (source: NIAD-QE, 2016).

document-based admissions were more likely to express a need for FCE information. Figure 5 shows the variation among universities according to the types of credentials they required. The respondents at the universities that used document-based admission processes were more likely than the others to report a need for information on accreditation status and curricular systems. Those that required international applicants to take entrance examinations seemed to put more emphasis on their institutional entrance examinations than on submitted credentials. The respondents also apparently cared about the authenticity of documentation and expressed a need for FCE information to assess the qualifications and credentials of the international applicants.

In addition, the respondents that reported more need for FCE information were at universities with more transfer admissions from foreign institutions without institutional credit-transfer agreements. As pointed out above, most of the respondents did not suspect the authenticity of foreign credentials. However, Figure 6 shows that the respondents tended to check the accreditation status 


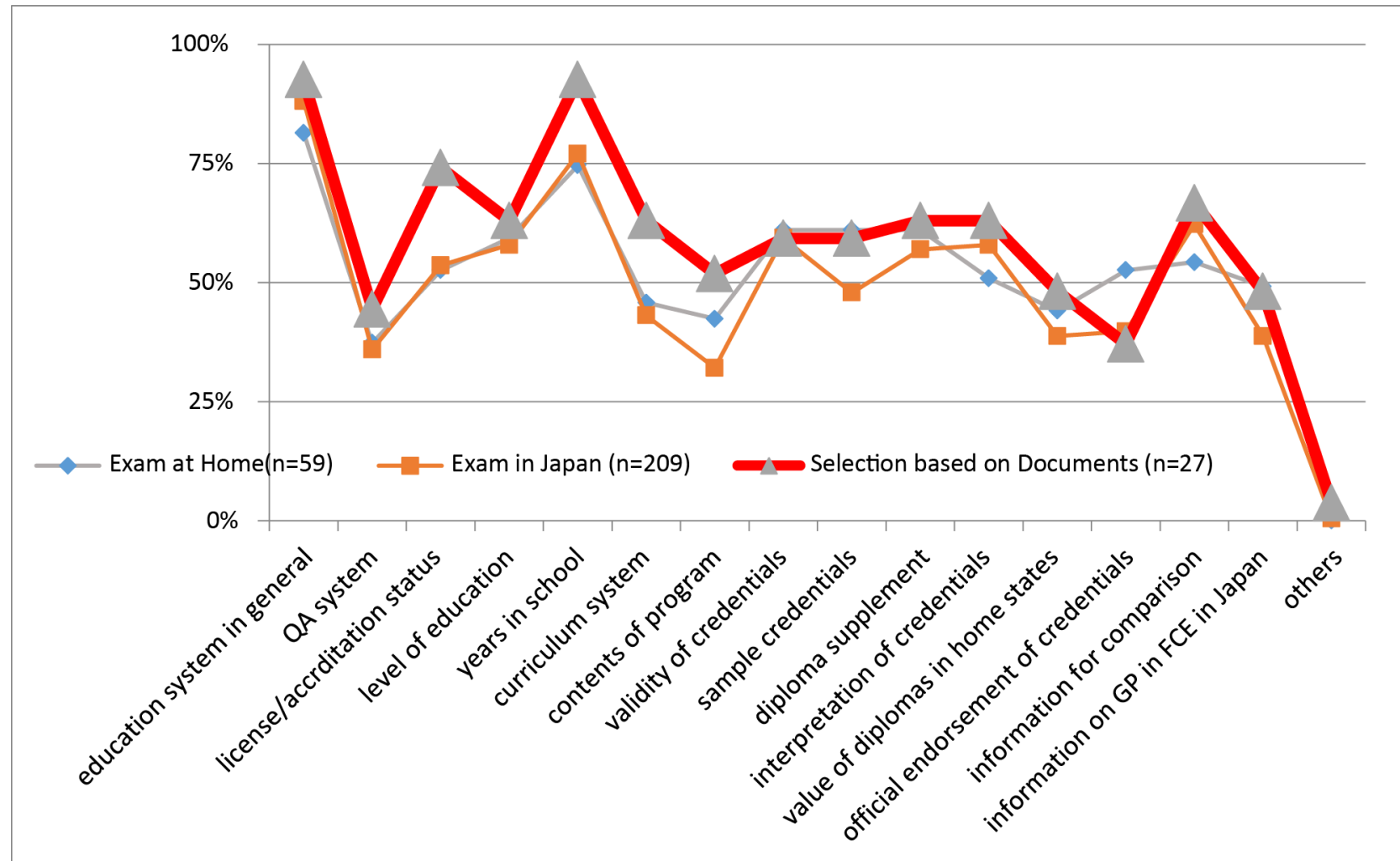

Figure 5. Various aspects of need for foreign credential evaluation by type of admission system. (source: NIAD-QE, 2016).

\section{Question:}

"How often do you check accreditation status of an applicant's home institution without institutional credit-transfer contract?"

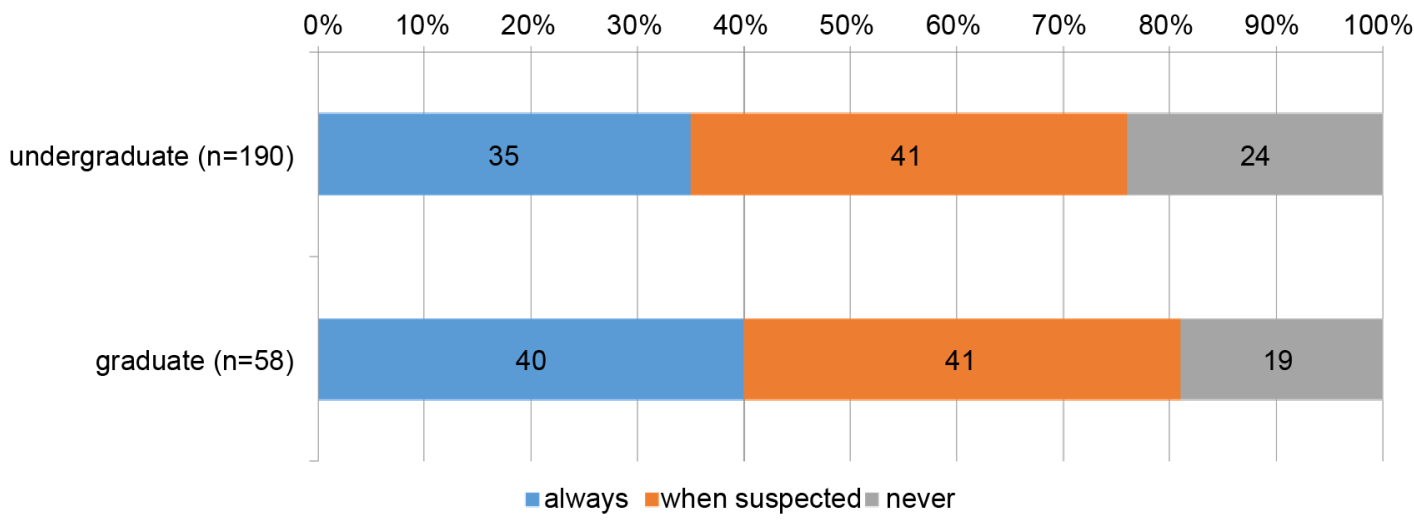

Figure 6. Attitude toward prospective students from institutions with and without credit-transfer contracts (source: NIAD-QE, 2016).

more often when the prospective student was a transfer admission candidate from a foreign institution without such an agreement.

Although some of the respondents at universities with relatively large proportions of international students had implemented FCE, the respondents reported that their sources of FCE information were limited. Figure 7 shows that 59\% of 
the respondents at the undergraduate level and $62 \%$ of the respondents at the graduate level depended on staff to assess applicants' qualifications and credentials. The second most common source was the respondents' personal knowledge and experience. About $42 \%$ of the respondents at the undergraduate level and about $34 \%$ of the respondents at the graduate level reported that they relied on themselves. It is not surprising that about two-thirds of the sample reported a need for NICs to obtain reliable FCE information (Figure 8). Although most of the sample reported no strict FCE and their stated need for FCE information was not high, the respondents at universities with relatively high proportions of international students expressed a need for NICs.

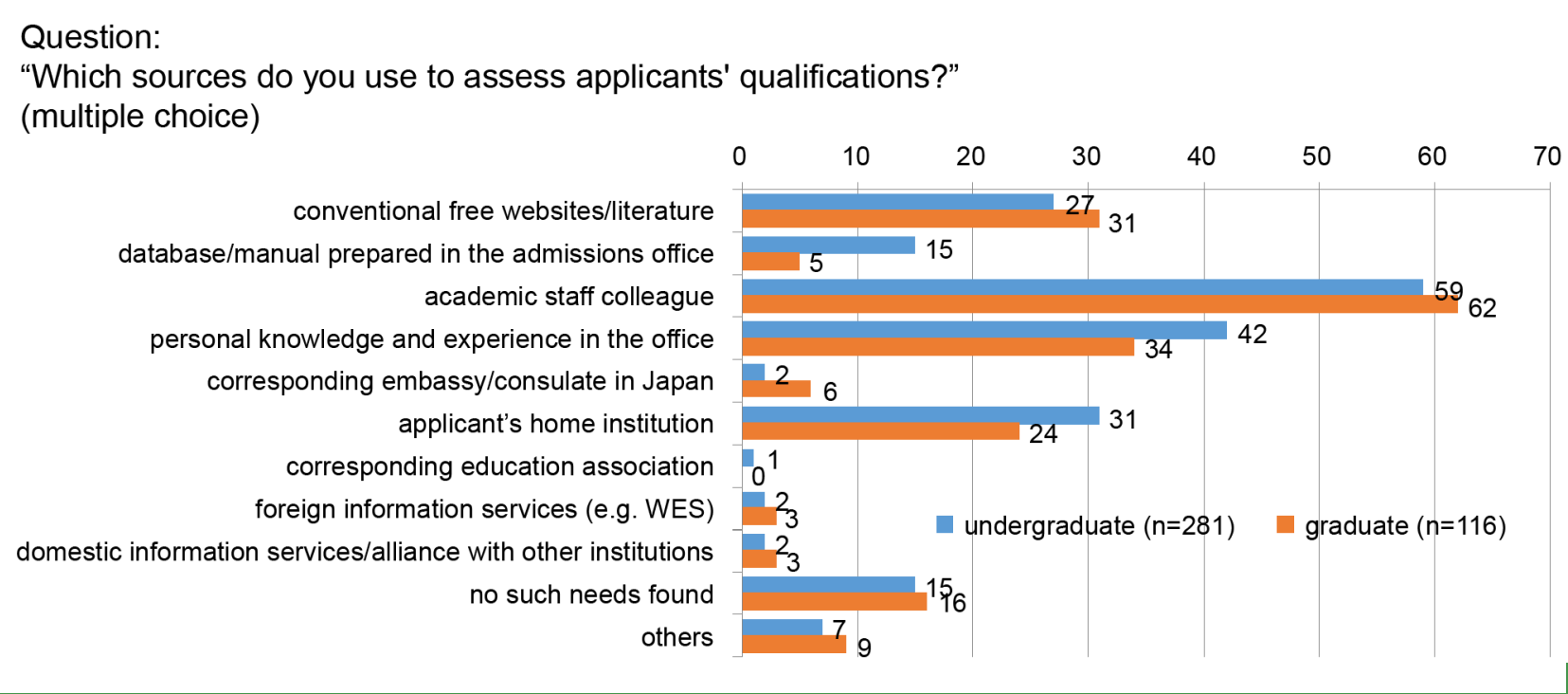

Figure 7. Sources of foreign credentials evaluation information (source: NIAD-QE, 2016).

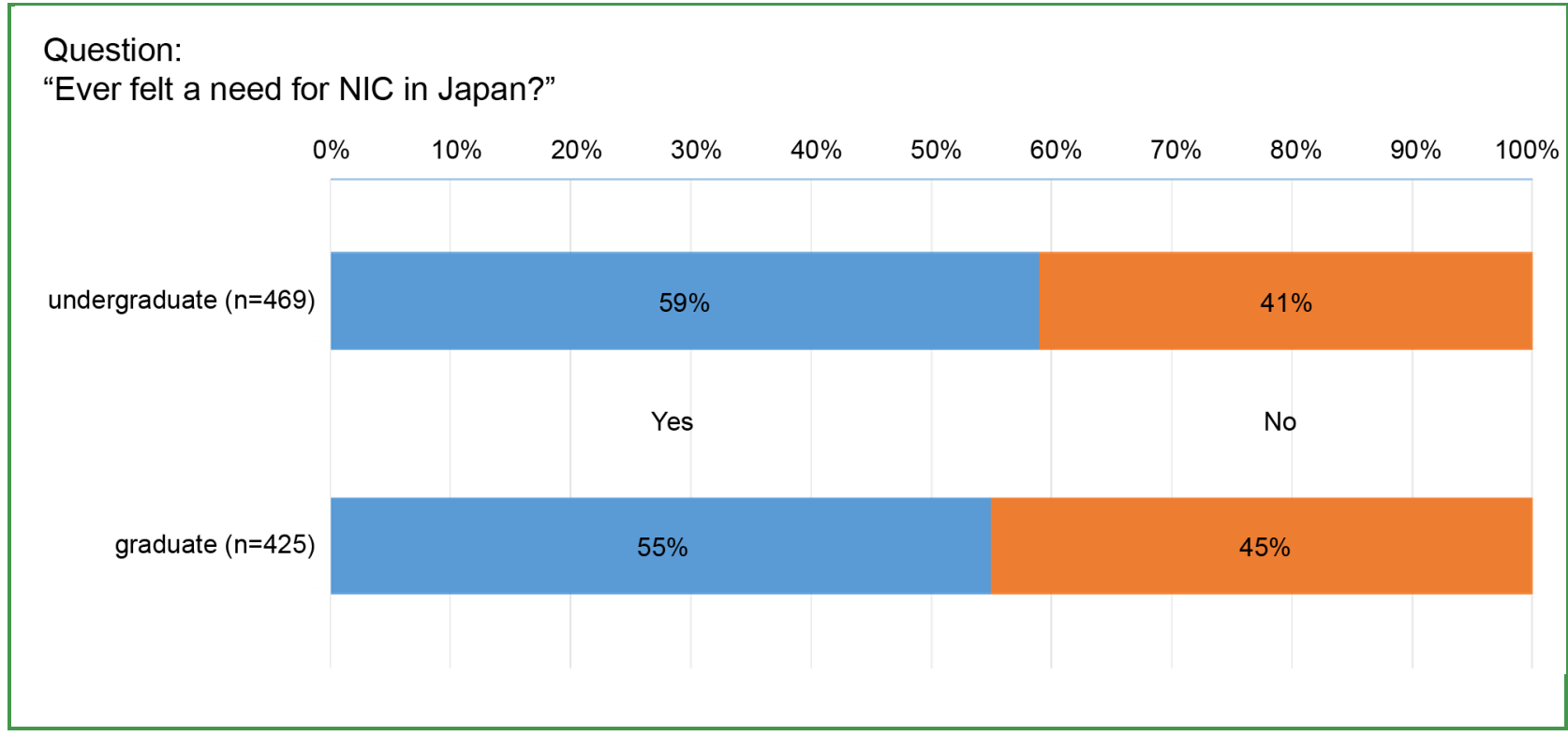

Figure 8. The need for national information centers in Japan (source: NIAD-QE, 2016). 


\section{The Need for Japanese NICs}

The NIAD-QE conducted a second survey, which focused on the need for Japanese NICs. This survey obtained detailed information on Japanese higher education (NIAD-QE, 2016). The survey was administered online from October 24 through November 28, 2014. The target population was 57 NICs located in Western countries that had ratified the Lisbon Recognition Convention. Twenty-four NICs responded (response rate: 42\%). The respondents reported difficulty dealing with Japanese credentials (Figure 9). The language differences were the largest obstacles to the ability to assess prospective Japanese students' credentials. The respondents also tended to have difficulty assessing Japanese credentials because of insufficient provision of basic information, such as the type, accreditation, and existence of the institutions. The NICs in the sample tended to rely on official websites for basic information about Japanese universities (Figure 10). According to the survey, the websites of Japan's Ministry of Education (MEXT) and the International Association of Universities (IAU) were used most often. The UNESCO Portal to Recognized Higher Education Institutions also was a popular source of basic information.

Although the respondents reported some difficulties assessing prospective Japanese students' qualifications and credentials, they seldom mentioned a need for Japanese NICs, probably because most Western NICs seldom need information on Japanese credentials (Table 2). Only the United Kingdom and New Zealand reported handling more than 100 cases of Japanese credentials per year. Considering the infrequency of their needs, it is reasonable that these NICs did not report strong interest in Japanese NICs.

\section{Implications}

Considering the reported low level of need for FCE in Japan, it is understandable that Japan took six years to ratify the Tokyo Convention. The survey data

\section{Question:}

"What do tou find difficult in assessing Japanese credentials?"

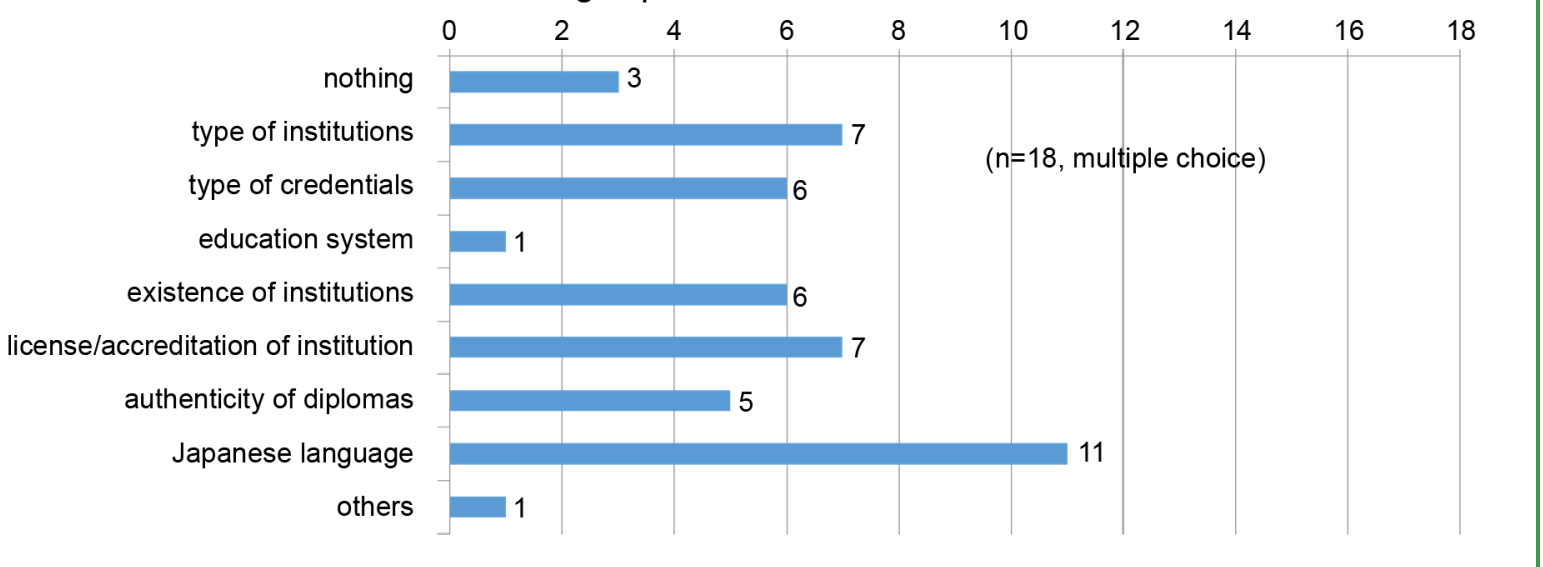

Figure 9. Difficulties assessing Japanese credentials (source: NIAD-QE, 2016). 


\section{Question:}

"Which sources do you rely on in assessing Japanese credentials?"

database prepared in the office database prepared by other NICs*

UNESCO

IAU(WHED)

ANABIN

MEXT

Study in Japan

JASSO

NIER

JUAA

NIAD-UE

JIHEE

JACA

others

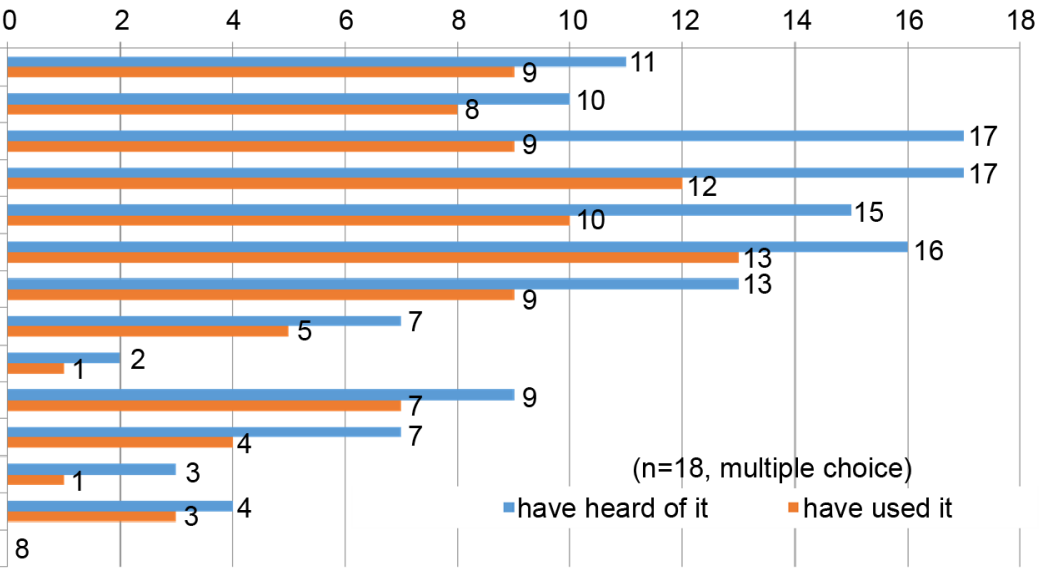

Figure 10. The sources for basic information about Japanese universities (source: NIAD-QE, 2016).

Table 2. Frequency of handling Japanese students' educational credentials.

\begin{tabular}{cl}
\hline Times per year & \\
\hline 100 or more & UK, New Zealand \\
$50-99$ & Germany \\
$20-49$ & Australia \\
$10-19$ & Norway, Denmark \\
$1-9$ & Estonia, Finland, Greece, Poland, Ukraine, Bulgaria, Switzerland, unknown \\
0 & Croatia, Ireland, Slovenia, Belgium \\
\hline
\end{tabular}

Source: NIAD-QE (2016).

indicated that most of the respondents did not express a need for FCE. More than $90 \%$ of the sample had never suspected the authenticity of documents submitted by international applicants. Moreover, the survey of NICs found that most of the NICs, which were in Western countries, were infrequently handling Japanese credentials, suggesting the reason that these NICs rarely reported a need for Japanese NICs to provide detailed information on Japanese higher education.

These findings imply that the low level of need for FCE might relate to the slow ratification of the Tokyo Convention in Japan and the other UNESCO Asia-Pacific member states. The five states (Australia, China, Japan, New Zealand, and South Korea) that had ratified the Tokyo Convention by January 2018 had relatively large proportions of international students. For example, Australia accepted about 294,000 international students in 2015, making it the most common destination for international students in Asia and the Pacific (OECD, 2017). Japan also accepted 132,000 students from foreign countries in 2015 (OECD, 2017). Both countries face challenges evaluating and ratifying foreign 
students' qualifications and credentials. The other UNESCO Asia-Pacific member states have smaller numbers and proportions of international students and FCE might seem relatively unimportant, which leads these states to delay ratification.

Increasing internationalization in higher education seems to be key to extending FCE to these countries. The survey found that Japanese universities with relatively large proportions of international students strictly implemented FCE. The higher the proportion of international students, the more the respondents perceived a need for FEC. Similarly, the perception that FCE is important increased as the number of document-based admissions and international transfers increased. It also is reasonable that non-Japanese NICs would be increasingly interested in NICs in the Asia-Pacific states as their numbers of Asia-Pacific student applications increase. Admissions officers will have more problems assessing their qualifications and credentials as their numbers grow. In anticipation of these changes, Japan should provide additional information on its colleges and universities in English because the survey found that the Japanese language and insufficient basic information were major barriers to evaluating Japanese qualifications and credentials.

\section{Conclusion}

For many countries in the Asia-Pacific region, the extent of students' international mobility might not be sufficient to encourage ratification of the Tokyo Convention because it might not seem important to systematically evaluate and recognize foreign credentials. To promote the Tokyo Convention, it can be said that "the more haste, the less speed." It might be best to first focus on promoting student mobility, which might, in turn, encourage ratification of the Tokyo Convention.

This is the first paper to summarize and assess the NIAD-QE surveys on the need for FCE and NICs in Japan, although the surveys were conducted a few years ago. These surveys provide valuable information on the actual need for FCE and the needs of NICs, but they never have been reported outside of Japan. This paper introduced these data to identify clues to the promotion of the Tokyo Convention. Assessing causal relationships and predictions is beyond the scope of this descriptive study. Further studies are needed to empirically test the observations made in this paper. For example, the low level of need for FCE might relate to lack of ratification of the Tokyo Convention in UNESCO Asia-Pacific member states other than Japan. Countries that face challenges in evaluating and ratifying foreign credentials were expected to have more positive attitudes toward the Tokyo Convention, which is an empirical question to be tested. Countries with numbers of inbound students that are relatively large, such as Malaysia, would, therefore, be next to ratifying the Tokyo Convention. As student mobility within the Asia-Pacific region increases, more Asia-Pacific countries are expected to ratify the Tokyo Convention. 


\section{Acknowledgments}

I am grateful to the anonymous reviewers of this paper for their helpful comments and suggestions on the manuscript. The preparation of this article was supported by Toyo University and MEXT/JSPS KAKENHI Grant Number $16 \mathrm{H} 03784$.

\section{References}

Chao, R. (2017). Why Asian States Need to Ratify the UNESCO Convention. University World News, No. 461.

http://www.universityworldnews.com/article.php?story=20170523230535494

Ifuku, R., \& Hata, E. (2015). Exploring Fair Assessment and Recognition of Foreign Qualifications and Prior Learning: Reports from the Results of Questionnaire Survey Targeted at Japanese Universities on Assessment of Foreign Credentials and Recognition of Credits Earned at Foreign Educational Institutions. Ryugaku Koryu, 47, 1-17.

Mori, R., \& Yoshikawa, Y. (2017). Demand for Information on Higher Education Qualifications in Japan: For Future Development of FCE and NIC. Seminar and Workshop on International Comparison of Foreign Credential Evaluation (FCE) in Higher Education, Toyo University, Tokyo, 25 January 2017.

NIAD-QE (2016). Final Report of Research on Development of an Appropriate Information-Provision System for Domestic and Foreign HEIs to Support Student Mobility (2013-2015). http://www.niad.ac.jp/n_kokusai/publish/rsc

OECD (2004). Quality and Recognition in Higher Education: The Cross-Border Challenge. Paris: OECD.

OECD (2017). Education at a Glance 2017. Paris: OECD.

UNESCO (2012). Asia-Pacific Regional Convention on the Recognition of Qualifications in Higher Education. Paris: UNESCO.

UNESCO (2017). Japan's Deposit of Instrument of Accession Makes the Tokyo Convention Very Close to Enter into Force.

https://en.unesco.org/news/japan-s-deposit-instrument-accession-makes-tokyo-conve ntion-very-close-enter-force

UNESCO (2018). Ratification by the Republic of Korea of the Revised Asia-Pacific Regional Convention on the Recognition of Qualifications in Higher Education (Tokyo, 26 November 2011).

http://portal.unesco.org/en/ev.php-URL_ID=49448\&URL_DO=DO_TOPIC\&URL_SE CTION=201.html

\section{List of Abbreviations}

FCE: Foreign Credential Evaluation

IAU: International Association of Universities

MEXT: Japanese Ministry of Education, Culture, Sports, Science and Technology

NICs: National Information Centers

NIAD-QE: Japanese National Institute for Academic Degrees and Quality Enhancement of Higher Education 